\title{
TFP, Costs, and Public Infrastructure: An Equivocal Relationship*
}

\author{
Eliana La Ferrara Massimiliano Marcellino \\ Bocconi University and IGIER
}

This Version: October 2000

\begin{abstract}
This paper studies the impact of public infrastructure on economic performance. We employ three different methodologies to estimate the returns to public investment. First, we relate growth in total factor productivity to accumulation of public capital. Second, we assess the role of public capital as an input to production. Third, we evaluate the reduction in costs that can be attributed to the presence of public infrastructure. Using regional data for Italy, we find that the aggregate impact of public capital is positive and significant under the first approach, slightly negative under the second, and virtually zero under the third. More coherent results obtain when disaggregating by geographical area and time period: under all three approaches, the effectiveness of public investment seems to be increasing over time and to be higher in Central and Southern regions than in Northern ones.
\end{abstract}

J.E.L. Classification: H54, O47, C50

Keywords: infrastructures, TFP, growth, costs

\footnotetext{
${ }^{*}$ We are grateful to Tito Boeri, Francesco Daveri, Riccardo Faini, Francesco Giavazzi, Vittorio Grilli, Lucio Picci, Guido Tabellini and participants at an IGIER - Ministero del Tesoro Conference and at a seminar at Harvard University for useful comments on an earlier version. We also thank Federico Bonaglia for outstanding research assistance, and Luca Opromolla for editorial assistance. Financial support by Bocconi University is gratefully acknowledged. Corresponding author: Massimiliano Marcellino, IEP, Università Bocconi, Via Salasco 3/5, Milano, Italy. Phone: +39-0258363327. Fax: +39-02-58363302. E-mail: massimiliano.marcellino@uni-bocconi.it .
} 


\section{Introduction}

The role of public infrastructure in stimulating productivity growth and reducing production costs has received increasing attention from both policy makers and researchers. The former have generally maintained that public capital enhances economic performance, and have been mainly concerned with where to invest, in what, and how much. The latter, on the other hand, have recently taken a step back and investigated whether a positive effect of public capital can indeed be taken for granted. Findings on this point have been mixed, depending on the theoretical models, econometric techniques, and datasets used. The ambivalence of the results challenges the rationale for public infrastructure provision as an input in the growth process, a serious issue for policymakers. This paper attempts to shed light on the relationships between public infrastructure, total factor productivity and production costs, both in theory and in practice. From a methodological point of view, our contribution is a critical comparison of the main competing approaches to evaluating the returns to public investment, highlighting the conditions under which they should yield the same results. On the empirical side, we implement the different methodologies using the same dataset, a task that, to the best of our knowledge, has not yet been undertaken.

The setting in which our empirical analysis is carried out is Italian regions in the period 1970-94. This setting is particularly interesting in view of the growing efforts on behalf of European institutions to integrate the economies of member countries and promote growth in relatively backward areas. In fact, Italy reproduces within itself many of the contrasts and differences that exist among European countries: the productive structure and the level of development of Italian regions varies widely, going from the rich and industrialized regions of the North to the relatively poor regions of the South. Understanding the differential impact of infrastructure investment in these areas can therefore shed some light on the role that public investment at the European level can serve to promote economic growth in relatively backward regions. In this sense, our analysis shares the motivation of the work by De la Fuentes and Vives (1995), who have studied the role of public investment in education and infrastructure in reducing regional disparities in Spain.

Broadly speaking, the existing empirical literature can be grouped into three methodological strands. First, there have been studies relating public capital accumu- 
lation to the growth rate of total factor productivity (TFP), computed as a residual from growth accounting (e.g., Hulten and Schwab (1984, 1991)). Second, public capital has been included as an input in the production function, and its marginal returns have been estimated (e.g., Aschauer (1989a, 1989b), Munnell (1990a, 1990b), Holtz-Eakin (1994), Evans and Karras (1994)). Third, the contribution of infrastructure investment to reducing production costs has been assessed (e.g., Morrison and Schwartz (1994, 1996), Seitz and Licht (1995)). The empirical results differ not only across methodologies, but also within the same approach. Hulten and Schwab (1991) find a weak relationship between the growth rates of TFP and of public capital. Aschauer (1989a), on the contrary, reports evidence in favor of a high and significant elasticity of production to public capital, i.e. approximately .35. Munnel (1990a) also finds a similar estimate for this elasticity when using data for the US as a whole, but a lower value (around .15) when using state level data. Within the same production function framework, Holtz-Eakin (1994) and Evans and Karras (1994) show that, when controlling for state specific effects, public capital does not seem to play a significant role. Finally, Morrison and Schwartz $(1994,1996)$ report a positive but quantitatively limited impact of public infrastructure on cost reduction but find that, when they take into account the efficiency loss due to financing public investment through taxation, the net effect is close to zero. ${ }^{1}$

While the above studies use data from the United States, recently there have been studies on Italy (e.g., Picci (1995a), Rossi and Toniolo (1993), Bonaglia, La Ferrara and Marcellino(2000)). Within the production function approach, Picci (1995a) uses regional data for Italy and reports an elasticity of production to public capital of .43 and .35 with fixed and random effects, respectively. When performing robustness checks, however, he finds that this result is weakened. Rossi and Toniolo, following a cost function methodology with a century long dataset (1880-1980), focus more on the relationships among production inputs, and find that public and private capital are substitute in the short run but become complement in the long run for most of the sample period. Finally, Bonaglia et al. (2000) estimate the impact of different categories of public capital (e.g. transportation, sanitation and education) on economic

\footnotetext{
${ }^{1}$ For a model in which the costs and benefits of public capital are embodied in an endogenous growth framework, see Barro (1990).
} 
performance, and find different results depending on the methodology used.

It is difficult to assess whether the discrepancy in the above results, both for Italy and for the US, is due to the different methodologies used by the various studies, to different data sets, or to some other factor. A first goal of the present study is to apply all the existing approaches consistently to the same data set (Italian regional data for the period 1970-94), in order to isolate the potential sources of ambiguity in the results. Furthermore, we specify the conditions under which, from a theoretical point of view, we can expect to find a correspondence among the quantitative values of the parameters estimated with the various approaches, and we test these correspondences in our data. Finally, we attempt to analyze the impact of infrastructure at a more detailed level than the simple national level, by disaggregating our data in two ways. First, we run our regressions separately over various sub-periods, to allow for structural changes in the parameters over time. Second, we consider four Italian 'macroregions' separately, to account for the different economic and production structures that may prevail in those areas. In all cases, we control for potential endogeneity problems of the public capital variable by applying two-stage-least-squares, and we check the robustness of our results.

Our findings show first of all marked differences in the sources of growth in different geographic areas. Overall, the relatively high growth rates of the North East and the Center are mostly attributable to higher than average total factor productivity growth. Both labor and private capital in fact grew very little in those regions in the sample period. The South, on the contrary, had extremely low TFP growth rates and managed to achieve an average growth rate of real value added between 2 and 3 percent per year only thanks to significant private capital accumulation. Starting from these facts, we can expect to find interesting differences in the impact of public infrastructure on productivity in Northern, Central, and Southern regions.

On the pooled sample (regional time series data for the whole Italy) the three methodological approaches yield different results. Overall, public investment in infrastructure seems to have contributed positively to TFP growth (the share of TFP growth that can be attributed to public capital accumulation is estimated to be .45), while we fail to find a positive role for public capital as an input in the production function and in reducing costs. The estimated elasticity of costs to public capital for 
Italy as a whole is in fact -.02.

When we turn to disaggregated analysis, the results are more coherent across methodologies. Both the growth accounting and the production function approach suggest that public capital was least effective in the 1970s, and that its effectiveness has been improving over time. In terms of regional disaggregation, all three approaches indicate the Center and the South as the areas where infrastructure investment yields the highest benefits. This is particularly relevant in that those areas (especially the South) are less economically advanced compared to the North of Italy, so our analysis seems to support the scope for public investment in fueling economic development of relatively backward areas.

The remainder of the paper is organized as follows. In section 2 we present a theoretical framework for the analysis of the effects of public infrastructure. In section 3 we briefly comment on the Italian regional dataset that we use (more details can be found in the Data Appendix) and present descriptive statistics on the main variables of interest. In section 4 we develop the empirical analysis and discuss the results, while in section 5 we address issues of endogeneity and robustness of our estimates. Finally, in section 6 we summarize the main conclusions of this study and highlight its limitations and scope for future research.

\section{The theoretical framework}

In this section we briefly review the economic theory underlying the growth accounting, the production function, and the cost function approaches to infrastructure investment evaluation, both to provide a background for the interpretation of the results of the ensuing empirical analysis, and to highlight relationships, pitfalls and opportunities of the alternative methods.

\subsection{The Total Factor Productivity approach}

In the growth accounting literature, e.g. Hulten and Schwab (1984, 1991), the starting point is a production function that links real inputs to real output, under the assumption that factor remuneration equals their marginal product. With these hypotheses it is relatively straightforward to derive total factor productivity, and the 
question of interest is whether TFP can be at least in part explained by changes in the pattern of infrastructure investment.

Let us define the factor inputs labor, private capital (capital henceforth), and public capital by $L, K$, and $K G$, while $Q$ denotes gross output. Inputs are transformed into output according to the production function $Q=A F(L, K)$, where $A$ indicates Hicks neutral technological progress. ${ }^{2}$ Under the hypothesis of profit maximizing behavior and competitive markets, the growth rate of $A$ is

$$
\dot{A}=\dot{Q}-S^{L} \dot{L}-S^{K} \stackrel{\bullet}{K}
$$

with $S^{L}$ and $S^{K}$ being the output shares of labor and capital. With constant returns to scale, the sum of $S^{L}$ and $S^{K}$ is 1 . All the terms in the right hand side of equation (1) are known, and can be used to measure the growth in the index of technological progress, $\dot{A}$, usually referred to as TFP growth.

So far we have not considered the role of public capital, $K G$. The latter can both affect $A$, i.e., increase the productivity of the other factors as an externality, and it can be a direct (unpaid) input in the production function $F$, e.g., $Q=$ $\widetilde{A}(K G) F(L, K, K G)$, with $\widetilde{A}(K G)=\widetilde{A} K G^{\eta}$. In this case the growth rate of TFP is

$$
\stackrel{\dot{\tilde{A}}}{=} \dot{Q}-e^{L} \stackrel{\bullet}{L}-e^{K} \stackrel{\bullet}{K}-\left(\eta+e^{K G}\right) \stackrel{\dot{K}}{ } \mathrm{G},
$$

where $\eta$ is the elasticity of $A$ with respect to $K G, e^{x}$ is the elasticity of output to input $x(x=L, K, K G)$, and $\tilde{A}$ is "true" technological progress. Combining (1) and (2), we get

$$
\dot{A}=\left(e^{K}-S^{K}\right) \dot{K}+\left(e^{L}-S^{L}\right) \dot{L}+(\eta+e) \dot{K} G+\dot{\tilde{A}}
$$

Equation (3) is more general than standard specifications in the growth accounting literature. For example, according to Hulten and Schwab (1991), it is

$$
\dot{A}=\left(\eta+e^{K G}\right) \dot{K} G+\left(e^{L}+e^{K}-1\right) \dot{K}+\dot{A}^{*} .
$$

\footnotetext{
${ }^{2}$ Energy and intermediate inputs should also appear as arguments of $F$ (e.g. Berndt and Wood (1975)). Since data on these variables are not available on a regional basis for Italy, we make the usual assumption of separability (e.g. Chambers (1988)), and use data on value added instead of gross output in the empirical implementation.
} 
This simplification is valid when $e^{L}=S^{L}$ and $S^{K}=1-S^{L}$. Otherwise, biased estimators for the coefficients are obtained, and the direction and magnitude of the biases depend on the correlations among $\stackrel{\bullet}{L}, \dot{K}$, and $\dot{K} G$, and on the difference $e^{L}-S^{L}$.

Given the above arguments, the role of public infrastructure can be evaluated on the basis of the sign and significance of the coefficient of $\dot{K} G$ in a regression of $\dot{A}$ on $\dot{K} G, \dot{K}$, and $\dot{L}$, where $\dot{A}$ is computed from equation (1). From now on, we will refer to this approach as growth accounting.

\subsection{The production function approach}

A second way to evaluate the role of public capital is through what we may term a 'production function approach'. In agreement with the production function literature, e.g. Aschauer (1989a, 1989b) and Holtz-Eakin (1994), a Cobb Douglas specification is adopted. Services from public capital are considered as a direct factor input, usually proxied by the stock of available infrastructure, and the main question is whether the elasticity of output to this input is positive and significant.

Assuming that $K G$ is a direct input, and under the hypothesis on technological progress we made in the growth accounting framework $\left(A(K G)=A^{*} K G^{\eta}\right)$, we have

$$
q=a^{*}+\left(\eta+e^{K G}\right) k g+e^{K} k+e^{L} l
$$

where lower case letters denote logarithms. The question of interest is whether the overall elasticity of production to public capital, $\eta+e^{K G}$, is positive and significant.

Introducing hypotheses on the returns to scale, different specifications are obtained. With constant returns to private inputs only, it is

$$
q-l=a^{*}+e^{K}(k-l)+\left(\eta+e^{K G}\right) k g
$$

When there are constant returns to all inputs, we get the specification in Aschauer (1989b):

$$
q-l=a^{*}+e^{K}(k-l)+\left(\eta+e^{K G}\right)(k g-l) .
$$

In the case of overall decreasing returns to scale,

$$
q-l=a^{*}+e^{K}(k-l)+\left(\eta+e^{K G}\right)(k g-l)-\lambda l .
$$


where $\lambda=1-e^{K}-e^{K G}-e^{L}-\eta>0$. For increasing returns, it is $\lambda<0$.

In all cases the coefficient of $k g$ (or of $k g-l$, depending on the specification) is equal to that of $\dot{K} G$ in the growth accounting framework, equation (4). Yet, if invalid hypotheses on the returns to scale are made, the estimator of the coefficient of $\mathrm{kg}$ can be biased, as stressed by Holtz-Eakin (1994). Hence, if the hypothesis of a Cobb Douglas specification is correct and no invalid assumptions on the return to scale are made, the growth accounting and the production function approaches should lead to the same conclusions about the effects of public capital on TFP and output growth.

\subsection{The cost function approach}

The dual problem, i.e., whether there are substantial cost savings in the presence of public infrastructure has also received attention, e.g. Morrison and Schwartz (1994, 1996), Seitz and Licht (1995). The starting point is the specification of a cost function:

$$
C=G(K, K G, w, t, Q)+c K
$$

where $G$ is a variable cost function. Private capital, infrastructure, and output are included among its arguments to take into account fixity, availability of (free) public capital, and scale economies. Other arguments are the price of labor, $w$, and a linear trend, $t$, that proxies for technology improvements. ${ }^{3}$

The counterpart of marginal product in the cost function framework is the shadow value, i.e., the change in variable costs due to a marginal variation in an input. We label the shadow values of private and public capital as $z_{K}$ and $z_{K G}$, respectively, and define them as

$$
z_{K}=-\frac{\partial G}{\partial K}, \quad z_{K G}=-\frac{\partial G}{\partial K G}
$$

The corresponding elasticities are

$$
\varphi^{K}=-\frac{\partial \log C}{\partial \log K}=, \quad \varphi^{K G}=-\frac{\partial \log C}{\partial \log K G} .
$$

\footnotetext{
${ }^{3}$ Notice that we are assuming that $K G_{t}$ has a price of zero, so that it does not appear as a paid input in the total cost function $C$. Notice also that, while in the estimation of the production function output is endogenous and input quantity are exogenous, estimating a cost function implies the more realistic assumption that input quantities are endogenously determined, taking as given input prices (Berndt (1991), ch. 9).
} 
Because $K G$ only affects variable costs, it is $\varphi^{K G}=z_{K G} K G / C$, that can be interpreted as the shadow share of public capital.

The first order conditions for cost minimization imply that the optimal level of $K$ satisfies $z_{K}=c$, where $c$ is the user cost of private capital. Unfortunately a similar condition cannot be directly employed for the determination of public capital, first because the level of $K G$ cannot be decided by the firm, and second because its price for the firm itself is zero, assuming no direct links between the tax bill and infrastructure usage. Nonetheless, it makes sense to compare the shadow value of $K G$ with a measure of its opportunity $\operatorname{cost}$, say $c_{K G}$, in order to determine the optimal level of $K G$. A positive shadow value indicates that public capital reduces costs, but $z_{K G}$ should be at least as big as the social user cost, $c_{K G}$, for the investment to be convenient. Synthetic indexes to evaluate investment are

$$
E^{K}=\left(c-z_{K}\right) K / C, \quad E^{K G}=\left(c_{K G}-z_{K G}\right) K G / C .
$$

A positive value of $E$ signals over-investment, and a negative value under-investment.

To obtain an estimate of each of the quantities in (10), (11), and (12) we adopt first a Cobb Douglas cost function, in order to obtain results that are qualitatively comparable to those from the production function (see Appendix A for more details). Then we follow Morrison and Schwartz $(1994,1996)$ and assume a more flexible functional form, namely a generalized Leontief cost function (see Appendix B for details).

\section{The data}

In this section we briefly describe the data we use in our empirical analysis and then present some descriptive statistics and simple correlations to get a sense of the main patterns. For a full definition of the variables and sources the reader is referred to Appendix C.

\subsection{Data sources and definitions}

Throughout the analysis we use yearly data at the regional level, currently the smallest disaggregation level available in Italy for which there is sufficient time series data 
for all the variables. The sample period is 1970-1994. ${ }^{4}$ We concentrate on the regional industrial sector, which includes Industry in the strictest sense, Energy, and Constructions.

Our output measure is regional value added at constant 1990 prices. The series is built merging the ISTAT (1997a,b) data for 1980-95 with data from Fondazione EniEnrico Mattei (1994). Labor input is measured as total labor units, i.e. dependent and autonomous workers, in the industrial sector. Wages are taken to be equal to those of dependent workers, due to the absence of data on incomes of autonomous workers disaggregated by sector and region.

The stock of private capital is constructed with the perpetual inventory method. First of all, a benchmark stock of capital is constructed by summing investment flows over a number of years equal to the average economic life of the investment goods under consideration (e.g., 15 years for equipment and machinery, 10 years for transportation, 50 years for constructions). ${ }^{5}$ Starting from this initial value, the capital stock for every year is obtained by adding investment in that year, and subtracting the value of capital goods that become obsolete in that year.

The stock of public capital disaggregated by region and category is taken from Bonaglia and Picci (1999). They apply the perpetual inventory method to regional time series for executed public investment (published in Istat (1954-1992)) to apportion the aggregate capital stock estimated by Rossi, Sorgato and Toniolo (1993). The categories of public capital included are the following: Land (e.g., land reclaimation and irrigation); Communications; Education (e.g., buildings for educational and social activities); Water (e.g., river planning); Sanitation (e.g., sewers, water filtering, hospitals); Roads; Railways (e.g., railways and subways); Marine (e.g., ports, lake and river navigation); Other (e.g., gas-pipelines, infrastructures for tourism). As for the source of financing, the data includes public works financed by the State (Ministries and Cassa per il Mezzogiorno); Public Adiministration (Regional, Provin-

\footnotetext{
${ }^{4}$ Of course, to build capital stocks we use data going back to before 1970, so 1970-94 must be intended as the period covered by our regressions. Unfortunately, data availability on public capital constrains our period to end in 1994.

${ }^{5}$ For a review of the average lives of different categories of investment goods in various countries, the reader is referred to Rosa and Siesto (1985). Another useful reference on the perpentual inventory method is ISTAT (1995).
} 
cial, and Municipal governments; INPS, INAIL); Public Companies and other public organizations.

A drawback of using the permanent inventory method to measure public capital is that the resulting stock is systematically overestimated for those regions that are least efficient in the use of public funds. Ideally, one would want a physical index of public capital stock for each region and each year. Unfortunately such data does not exist for Italy: the only physical indexes we are aware of are those by Bracalente and Di Palma (1982) for the year 1977, and by Biehl et al. (1990) for 1970 and 1987. Preliminary evidence by (Picci (1995b) shows that southern regions are ranked systematically higher with the permanent inventory method than with physical index. Despite these discrepancies, we are forced to use the investment-based measure due to lack of data. Notice that as a consequence of the possible over-estimation of $K G$ for Southern regions, one could find downward biased regression coefficients.

Next, following Hall and Jorgenson (1967) and King (1972), we define the user cost of private capital as

$$
c=p_{K}^{E}(r+\delta)
$$

where $p_{K}^{E}$ is the 'effective price' of private capital, i.e., the investment deflator adjusted for taxation and subsidies (see appendix B for a precise definition); $r$ and $\delta$ are, respectively, the rate of return and the depreciation rate. The construction of a 'social user cost' of public capital, $c_{K G t}$, is a controversial issue (see e.g., Harper et al. (1989), Ballard and Fullerton (1992)). We choose to compute $c_{K G t}$ with a similar formula to (13), except that in place of $p_{K}^{E}$ we use the public investment deflator; $r$ and $\delta$, instead, are assumed to be the same as for $c .^{6}$

Finally, TFP growth is calculated as in equation (1), where $S^{L}$ is the share of total labor compensation on value added, and $S^{K}=1-S^{L}$. Notice that $S^{L}$ includes compensations for both employees and self employed, where average earnings for self employed are assumed to be the same as for employees. We can not adjust for factor utilization, due to the lack of data. In fact, the two most commonly used corrections

\footnotetext{
${ }^{6}$ Morrison and Schwartz (1996a, 1996b) compute the user cost of public capital in a similar way, but they adjust it for the marginal efficiency cost of financing public investment through taxation. We do not know of any reliable estimate of the latter for Italy, hence we omit this adjustment in our calculation.
} 
for factor utilization, namely hours worked for labor and electricity consumption for capital, are not available at the regional level for the whole sample, to the best of our knowledge. Yet, inclusion of time dummies in the regressions may capture cyclicality and attenuate the problem.

\subsection{Output, private inputs and TFP}

In Table 1 we present descriptive statistics on the growth rate of real value added, and on its decomposition into the share attributable to private capital, labor and TFP. These values correspond, respectively, to $\dot{Q}, S^{K} \dot{K}, S^{L} \dot{L}$, and $\dot{A}$ in expression (1). We also report the growth rate of public capital. The figures are disaggregated by period, and by macroregion, i.e. North West, North East, Center, and South. Details on the composition of the macroregions can be found in Appendix C.

\section{[Insert Table 1 here]}

Over the whole period 1970-94 the annual growth rate of real value added was on average $2 \%$. The worse performance was in the North West $(0.9 \%)$, the best one in the North East $(2.9 \%)$ and the Center (2.5\%), while the South grew at $1.9 \%$. These figures, however, hide substantial differences over subperiods: between 1970 and 1979, in fact, Italian regions grew on average at a fast 3.1\%, while growth slowed down in $1980-89$ to about $1.7 \%$, and nearly stopped in 1990-94, when on average it was only $0.7 \%$ per year.

Turning to capital and labor, over the whole period the contribution of private capital to growth was one percentage point, while that of labor was -0.3 percentage points. The South is the area where the contribution of capital and labor was highest, respectively, 1.3 and -0.1 percentage points, while the North West suffered most from the decrease in occupation in the industrial sector. The outstanding growth performance of the North East in general cannot be only attributed to higher investment, since average private capital accumulation accounted for only 0.9 percentage points of growth. Over time, there is a clear decreasing trend in the contribution of both capital and labor to growth.

Average TFP growth is rather low (1.3\%), and constant across subperiods for the whole Italy. Yet, it is higher in the North East, where it reaches $2.2 \%$, and it is close 
to zero in the South $(0.6 \%)$. The Center has similar average TFP growth rates to the North-West, though the temporal pattern is rather different, with higher growth in the Center in the '70s, and viceversa in the '80s. The relative advantage of the North East - and disadvantage of the South - holds across all subperiods.

Overall the good relative performance of North Eastern and Central regions seems to be mostly attributable to higher than average TFP growth. The North West had a respectable TFP growth rate, but did markedly worse in terms of labor (and partly capital) accumulation. But the most striking fact is that overall the South had higher labor and capital growth rates than the North East $(4.4 \%$ and $-0.2 \%$ for South versus $3.4 \%$ and $-0.3 \%$ for North East), yet grew almost one percentage point less per year. A possible explanation for this pattern is the policy of incentives to private investment and hiring in the South. Some authors, e.g. Prosperetti and Varetto (1991), argue that this policy has led to 'overcapitalization' and, in general, to a relative inefficiency of southern firms compared to northern ones. Others, e.g., Del Monte and Giannola (1997), view the relatively high capital labor ratio in the south as a rational response by firms to the presence of higher costs of intermediate goods. ${ }^{7}$

The single most important factor responsible for the regional growth differentials appears to be TFP growth. Since Meade (1952), it has been widely recognized in the literature that public investment in infrastructure is one of the main potential determinants of TFP. As we can see from Table 1, the average annual growth rate of public capital in Italy was $2.7 \%$ over the period $1970-94$, more than 1.5 percentage points higher than that of private capital. It is also worth pointing out that, in all subperiods, public capital growth was higher in the Northern regions (about 3\%) than in the Center and in the South (2.3\% and $2.5 \%$, respectively). The widely held notion that the South receives a disproportionate share of public spending compared to the Center and especially the North must be understood as related to transfer payments as opposed to public investment in capital goods.

The pattern of growth of public capital over time is decreasing, with values of $3.2 \%$ in the ' $70 \mathrm{~s}, 2.5 \%$ in the ' $80 \mathrm{~s}$, and $2.1 \%$ in the early ' $90 \mathrm{~s}$. Though such a pattern could be correlated with the decrease in output growth, the decline is also present in

\footnotetext{
${ }^{7}$ In Del Monte and Giannola's view the relatively 'inefficiency' of southern firms is due to the fact that the latter are forced to integrate vertically, due to the higher costs of intermediate inputs, hence cannot take full advantage of specialization.
} 
the growth rates of private inputs. Hence, before drawing any conclusions on the role of public capital in enhancing growth, we need to take into account the interaction among all productive inputs, and turn to multivariate analysis.

\section{The role of public capital}

\subsection{Results from growth accounting}

In table 2 we report estimates of equation (4), namely, we regress TFP growth on the growth rate of public capital $(\dot{K} G)$ and of private capital $(\dot{K})$, with fixed effects included in the regressions. ${ }^{8} 9$ As already mentioned in Section 2, the coefficient on $\dot{K} G$ measures the overall elasticity of output with respect to public capital, $\eta+e^{K G}$. It is clear from the first column of table 2 that the elasticity is positive, rather high, 0.47 , and significant at $5 \%$. This means that, ceteris paribus, the effect of an increase of one percentage point in $\stackrel{\bullet}{K} G$ (e.g. from $2 \%$ to $3 \%$ ) on TFP growth - and therefore on output growth - is about 0.47 percentage points. The coefficient on $\dot{K}$ is negative, suggesting that the returns to private capital may be decreasing.

[Insert table 2 here]

We then estimate the regression separately for the periods 1970-79, 1980-89, and 1990-94; the results are reported, respectively, in columns 2, 3, and 4 of table 2 . The maximum impact obtains in the eighties, with an elasticity of TFP to $K G$ of .82; the lowest one is the seventies, with an elasticity of .24 , while the estimated value for the first half of the nineties is .53. In the light of this pattern, we can think that most of the skepticism regarding the productivity enhancing role of public capital comes from the experience of the 1970s, rather than from the most recent years. As

\footnotetext{
${ }^{8}$ We started with the more general equation (3), but $\dot{L}_{t}$ was never significant (results are available). There also appears to be no need of random effects (the Breusch Pagan test yields a p-value of .53). The low values of $R^{2}$ obtained in our regressions are common to the literature (e.g., Hulten and Schwab (1991)), and likely depend on the fact that the dependent variable is a residual.

${ }^{9}$ The empirical results for the growth accounting and the production function approaches are obtained with Stata 5.0. For the cost function estimation we used TSP 4.1. The programs and detailed results are available upon request.
} 
we will see, the temporal pattern of increasing effectiveness of public capital in recent years will also emerge from the production function approach. Among the potential explanations for such a pattern, improved administrative efficiency is likely to have played a non negligible role.

In the last four columns of table 2, we pool again the years and disaggregate over macroregions. The coefficient on $\dot{K} G$ is positive (but not significant at conventional levels) for the North West and the Center, positive and significant for the South, and negative and insignificant for the North East. The estimated elasticity is particularly high for the South, .62. On the other hand, the impact of $\dot{K}$ is generally negative (positive for the North East), though again not significant, except for the South. The fact that we find statistically significant values for Italy and for the South, but not for the other macroregions, is likely due to the different sample sizes.

\subsection{Results from the production function approach}

We now illustrate the empirical results that arise from the production function approach. Table 3 reports the estimated coefficients for a Cobb Douglas specification as in equation (5), using fixed effects and time dummies. ${ }^{10}$ From the first column of table 3 , the elasticity of output to public capital, $e^{K G}$, for Italy is negative, while that to private capital is positive and significant, 0.14. Repeating the analysis over different subperiods, however, we can see that the negative impact of public capital on output only holds for the Seventies, while in the Eighties and Nineties such impact is significantly positive and increasing (the estimated coefficient on the $\log$ of $K G$ for these periods is, respectively, .17 and .56). The temporal pattern of the effect of public capital is broadly similar to that of the growth accounting approach.

\footnotetext{
${ }^{10}$ The hypothesis of fixed versus random effects is often rejected, yet the regressors appear to be correlated with the random regional errors. Hence, we prefer to focus on the fixed-effects model, that yields consistent, even though, not efficient estimators. Cyclical fluctuations need also to be accounted for, in order to avoid spurious correlations. To evaluate whether there is any cyclicality left after inclusion of the time dummies (which also allow to account for exogenous changes in the rate of growth of technological progress), we have tried including inventories as an explicit cyclical variable. However, inventories do not improve our explanatory power in any way, hence we do not keep them in the final specification. Notice that the reported high values of $R^{2}$ in table 3 are due to the time dummies.
} 
[Insert Table 3 here]

Further useful information can be gained from regional disaggregation. Columns 5-8 of table 3 report results for the four macroregions, using regional and time dummies. It turns out that public capital is mostly productive in the South, followed by the Center, and not productive in the North East and North West.

The last row of table 3 reports the p-value for the test of constant returns to all inputs. The null of constant returns is accepted at the 5 percent for the '70s and the '90s, and rejected for the '80s. In terms of geographical areas, the hypothesis is accepted for the Center and the South, rejected for Northern regions.

A potential objection to our interpretation of the above results is that the positive correlation between public capital and production may work through demand as opposed to supply. To discriminate among the two channels, one may want to exploit the fact that demand effects are likely to take place at the time the investment is undertaken, while the impact on supply can be expect to last longer. To perform a test along these lines, one would need either project level data or a long enough time series to allow for estimation of dynamic models with a sufficient number of lags. Unfortunately, neither is currently available. However, we believe that the supply side interpretation can be maintained for two main reasons. First, to the extent that the expansionary effects of public investment translate into increased labor demand and private investment, they should already be taken into account by the fact that we include $L$ and $K$ as inputs in the production function (and explanatory variables in the regressions). Second, our empirical results on the time pattern of public capital effectiveness go in the opposite direction to what a demand side interpretation would suggest. In fact, public investment was higher in the '70s than in the '80s, which should have led to a bigger impact on demand, while both the production function and the growth accounting approaches yield higher coefficients on public capital for the ' 80 s as compared to the '70s.

\subsection{Results from the cost function approach}

Having considered the effects of public capital on output growth, we now evaluate its role in cost reduction. This requires estimating the system of equations reported in Appendix A. The resulting parameter estimates are not of direct interest (they 
are available upon request), but they are useful to calculate the shadow values of the capital inputs $\left(z_{K G t}, z_{K M t}, z_{K B t}\right.$ in (10), where $K M$ and $K B$ are private capital in equipment/machinery and buildings, respectively), and the cost elasticities, $\varphi^{K G}$ in particular (equation (11)). A comparison of the shadow values with the user costs of private and public capital then provides information on whether under-investment $(E<0$ in $(12))$ or over-investment occurred $(E>0)$. These quantities are calculated for each year but, due to the space constraint, we only report the average values over the sample under analysis.

[Insert table 4 here]

The first column of table 4 presents results from panel fixed effects estimation, for the whole period 1970-94. ${ }^{11}$ The variable $\varphi_{K G}$, which is the cost elasticity to public capital taken with the opposite sign, should be positive for $K G$ to be cost reducing. Instead, the estimated value for Italy is negative, though very close to zero. As a result, $E^{K G}$ is positive, .27, suggesting over-investment in $K G$ at the national level. $E^{K B}$ is also positive, while $E^{K M}=-.02$, suggesting under-investment in machinery.

Repeating the analysis over subperiods, $\varphi_{K G}$ is positive only in the '70s, and negative in later periods. Even for the first period, however, the cost reducing effect of public capital is not sufficient to cover its social user cost: in fact $E^{K G}$ remains positive. On the other hand, $E^{K M}$ and $E^{K B}$ are only negative, respectively, in the ' 80 s and in the early '90s.

Noticeable differences across macroregions also emerge. From table 4, columns 58 , the best performance is in the Center, followed by the South, while the estimated values of $\varphi_{K G}$ are negative for the North-East and, in particular, for the North-West. Again, when we take into account the opportunity cost of infrastructure investment, $E^{K G}$ is positive even for the Center. The latter results could be due to overestimation of the user cost of public capital, $c_{K G t}$, that is substantially higher than its private capital counterpart, c. As far as private capital is concerned, there appears to be under-investment in machinery in the North-West and in buildings in the NorthEast.

\footnotetext{
${ }^{11}$ We include a time trend in the regression because time dummies increase substantially the number of parameters without affecting the goodness of fit of the model.
} 


\subsection{Comparing the results}

We should now pause to compare the estimates obtained under the three approaches. Comparing the TFP and the production function methods (tables 2 and 3, respectively), it is apparent that the latter gives estimates on the coefficient of $K G$ that are systematically lower than the former. Vice versa, the estimated coefficient on private capital in the production function approach is generally higher than in the growth accounting (notable exceptions are the North West and North East).

This second result is not surprising. In fact, we can see from equation (5) that the coefficient on $k$ in the production function approach is the elasticity $e^{K}$, while that on $\dot{K}$ is $\left(e^{K}-S^{K}\right)$ or $\left(e^{L}+e^{K}-1\right)$, depending on whether (3) or (4) is estimated. Therefore we should always be getting a lower coefficient on private capital from the growth accounting approach, possibly negative when there are decreasing returns to $K$ and $L$ (and in fact we can see from the last row of table 3 that a negative coefficient

on $\dot{K}$ occurs whenever the hypothesis of constant returns to scale is rejected and there appear to be decreasing returns to $K$ and $L$ ).

The different coefficients on public capital, on the other hand, are much harder to explain. In fact, as we showed in the theoretical section, both approaches should yield the same estimates, equal to $\left(\eta+e^{K G}\right)$. The only cases in which we obtain virtually identical estimates are the period 1990-94 for Italy, and the North East. In all other cases, the growth accounting method yields higher coefficients than the production function one. A possible reason is that in the production function specification we include a set of time dummies that may attenuate the explanatory power of $K G$ (in fact, when we leave the time dummies out, the coefficient on public capital increases substantially). Other reasons may have to do with influential observations or endogeneity, and we will address these points in the next section.

Overall, we can see that despite the discrepancy in the quantitative impact of public capital which we observe in some cases, the qualitative pattern that emerges from the two approaches is very similar. The effectiveness of public investment has increased over time (in particular, compared to the '70s), and the macro regions where such effectiveness is highest are, in the order, the South and the Center.

Turning to the cost function methodology, we cannot directly compare the estimates in quantitative terms, but again some qualitative features remain the same as 
in the other approaches. In particular, the South and the Center are still the areas where public capital is most effective (though the ranking among the two is now reversed). The time pattern is now markedly different, suggesting a decrease in the cost saving role of public capital from the '70s to the '80, and a slight improvement from the ' $80 \mathrm{~s}$ to the '90s (though still lower effectiveness than in the '70s). This difference may be due to differences in the specification of the model ${ }^{12}$, and also to the few degrees of freedom that remain when we estimate the cost system on subsets of the sample. In the next section we experiment with a more flexible functional form for the cost function, and we find that the temporal pattern found for the other approaches is reinstated.

\section{$5 \quad$ Causality and sensitivity analysis}

In this section we explore the robustness of our estimates to the presence of outliers, we deal with potential endogeneity problems and/or measurement error, and we address the issue of the functional form for the cost function approach.

In order to control for influential observations whose presence can sensibly bias the estimators, we calculate the DFbetas and drop the observations that lead to major changes in the parameters when included in the sample. ${ }^{13}$ Table 5 reports our estimates of the production function for the sample purged of influential observations. $^{14}$

\section{[Insert Table 5 here]}

Comparing these results with those obtained from the full sample (table 3 ), we find that the estimated coefficient on $K G$ is very similar for Italy as a whole, and fairly similar for the South (.28 as compared to .37 , both significant at the 5 percent level).

\footnotetext{
${ }^{12}$ In order to separate between variable and fixed costs, the Cobb Douglas in this approach only includes private capital in transportation, and not the total stock of private capital.

${ }^{13}$ In particular, we dropped those observations for which abs (DFbeta) $>2 / \sqrt{\# \text { obs }}$ (see Belsley et al. (1980), p.28).

${ }^{14}$ In this section, for expositional purposes we concentrate on the production function approach and perform the various possible tests. We have also repeated similar tests for the other approaches and no significant differences emerged. The disaggregation into subperiods is not reported because, once we drop the influential observations, we are left with too few observations for 1990-94.
} 
The coefficient for the Center is also positive, though not statistically significant, and that for the North is virtually zero. The most important difference emerges with respect to North-Eastern regions. While in the full sample we found a coefficient of -.14 on $K G$, when we drop influential observations the same coefficient is estimated to be .16 (significant at the 10 percent level). Nonetheless, the qualitative pattern of highest effectiveness of public capital in the Center and South as opposed to the North remains unchanged.

We next turn to the issue of potential endogeneity of public capital. We can think of two reasons why the link between output and public capital may go in the opposite direction to that hypothesized here. First, regions with higher output may be regions where $K G$ is systematically higher, for example because those are fast growing regions and public investment is more productive in an environment where technology grows faster. Second, public intervention may be targeted towards relatively poorer areas with the aim of improving incentives for private investment. In the former case, we can expect the OLS coefficient on $K G$ to be upward biased, in the latter to be downward biased. Another source of bias in the OLS coefficient for $K G$ would be measurement error. To cope with these problems, in table 6 we present two stage least squares of the role of public capital in production.

\section{[Insert Table 6 here]}

We use two instruments for $K G$ : $(i)$ a one-year lag of the stock of public capital for a given region (in logs), which we call KGlag; and (ii) the average contemporaneous stock of public capital in neighboring regions (still in logs), which we denote KGnb. Notice that with the latter instrument we lose two regions which are islands (Sicily and Sardinia). From the first column of Table 6, the coefficient on public capital for Italy is virtually identical to that found without instrumentation (first column of table 3). When we disaggregate the sample over macro regions, we find again a positive (though not statistically significant) coefficient on public capital for Central and Southern regions, and negative coefficients for the North West and North East (the latter two being very similar in magnitude to those obtained without instrumentation). We therefore conclude that our results hold when controlling for the potential endogeneity and measurement error in public capital, which is nonetheless important according to the outcomes of the Hausman test, reported in the last row of table 6. Two stage 
least squares on the sample purged of influential observations are reported in Table C.1 of Appendix C. In that table, no significant difference emerges.

Finally, in table 7 we explore the robustness of our results to the specification of a different functional form in the cost function approach. Following Morrison (1988) and Morrison and Schwartz (1994, 1996b), we assume that the variable cost function is a Generalized Leontief (analytical details are provided in Appendix B).

\section{[Insert Table 7 here]}

Compared to the results in table 4, where a Cobb Douglas specification was adopted, two main differences emerge. First, the temporal pattern is now in line with that suggested by the growth accounting and the production function approach: the effectiveness of public capital is now generally increasing over time, leading to the highest cost savings in the 1990s. Second, the pattern across macro regions is now different: the North East is now the area where public investment has the largest impact, while such impact is basically zero (or even negative) for the Center and the South.

\section{Conclusions}

The potential for a productivity enhancing role of public infrastructure has been highly emphasized in recent years. Yet, empirical evidence has been mixed at best. This paper attempts to conduct a systematic analysis of the impact of public capital on TFP, production, and costs by comparing the three main existing theoretical approaches, and implementing them with regional data for Italy.

At the national level, the first approach indicates a strong positive effect of public capital accumulation on TFP growth; the second approach gives a (small) negative elasticity of production to public capital; and the third approach indicates virtually no effect of public capital on variable costs. The results are more coherent across methodologies when we disaggregate the sample by time periods and by geographical areas. According to all three methodologies, the effectiveness of public infrastructure has increased over the years, especially in the 1980s compared to the 1970s. Also, all three indicate Central and Southern regions as the areas where public capital is most productive. 
An important caveat is in order. Our analysis is confined to the manufacturing sector, in the sense that the output measures or the costs which we use as dependent variables refer to that sector only. We cannot infer that our results would remained valid if a broader measure of output were used. Indeed, certain types of public investment (e.g., irrigation, land reclaimation, etc.) are most likely to have an impact on agricultural production than on the output of the manufacturing sector.

Scope remains for further work in several directions. First of all, it would be important to compare the benefits with an appropriate measure of the costs of public capital, taking into account for example the distortionary effects of financing public investment through taxation. Second, the criteria and procedures for financing public investment are likely to play a role in the efficiency of its allocation, and it could be interesting to explore these links. Third, analogous procedures to those we use could be employed to assess the impact of other types of public expenditures which in theory should be productivity enhancing, e.g. in law and order or higher education. Finally, a wider and more detailed set of data (e.g. at the provincial level) would be helpful to draw more accurate conclusions. 


\section{References}

[1] Aschauer D. (1989a), "Is Public Expenditure Productive?", Journal of Monetary Economics, Vol. 23, No. 2, 177-200.

[2] Aschauer D. (1989b), "Does Public Capital Crowd Out Private Capital?", Journal of Monetary Economics, Vol. 24, No. 2.

[3] Ballard and Fullerton (1992), "Distortionary Taxes and The Provision of Public Goods", Journal of Economic Perspectives, Summer 1992, 6(3), pp. 117-31.

[4] Barro, R. (1990), "Government Spending in a Simple Model of Endogenous Growth", Journal of Political Economy, 98(5), 103-25.

[5] Belsley, D.A., E. Kuh, and R.E. Welsch (1980), Regression Diagnostics, New York: John Wiley and Sons.

[6] Berndt, E.R. (1991), The Practice of Econometrics, Addison-Wesley.

[7] Berndt, E.R. and D.O. Wood (1975), "Technology, Prices and the derived Demand for Energy", The Review of Economics and Statistics, Vol. 57, No.3, 259268.

[8] Biehl, D., B. Bracalente, M. Di Palma, C. Mazziotta (1990), "La Diffusione Territoriale delle Infrastrutture: un'Analisi per l'Europa e per l'Italia", in M. Di Palma (ed.), Le Infrastrutture a Rete. Dotazioni e Linee di Sviluppo, Centro Studi Confindustria.

[9] Bonaglia, F. and Picci L.(1999), "Lo stock di capitale nelle regioni italiane", unpublished.

[10] Bonaglia, F., E. La Ferrara and M. Marcellino (2000), "Public Capital and Economic Performance: Evidence from Italy", Giornale degli Economisti (forthcoming).

[11] Bracalente, B. and M. Di Palma (1982), "Infrastrutture e Sviluppo Regionale in Italia: un'Analisi Multidimensionale", Note Economiche, 13-42. 
[12] Chambers, R.G. (1988), Applied Production Analysis, New York: Cambridge University Press.

[13] De la Fuentes, A. and X. Vives (1995), "Infrastructure and Education as Instruments of Regional Policy: Evidence from Spain", Economic Policy, 20, 13-51.

[14] Evans P., G. Karras (1994), "Are Government Activities Productive? Evidence from a Panel of US States", The Review of Economics and Statistics, 76, 1-11.

[15] Greene, W.H. (1997), Econometric Analysis, Prentice Hall.

[16] Hall, R.E. and D.W. Jorgenson (1967), "Tax Policy and Investment Behaviour", American Economic Review, 57(3), 391-414.

[17] Harper, M.J. , Berndt E.R. and Wood D.O. (1989), "Rates of Return and Capital Aggregation Using Alternative Rental Prices", in Technology and Capital Formation, eds. D.W. Jorgenson and R. Landau, Cambridge, MA: MIT Press, pp. 331.372 .

[18] Holtz-Eakin D. (1994), "Public-sector Capital and the Productivity Puzzle", The Review of Economics and Statistics, Vol. 76, No. 1.

[19] Hulten C.R. and R. M. Schwab (1984), "Regional Productivity Growth in U.S. Manufacturing:1951-78”, American Economic Review, Vol. 74, No. 1

[20] Hulten C.R. and R. M. Schwab (1991), "Public Capital Formation and The Growth of Regional Manufacturing Industries", National Tax Journal, Vol. 44, No. 4, pp.121-134

[21] Istat (1995), "Investimenti, stock di capitale e produttività dei fattori. Anni 1980 - 1994", Note e relazioni No. 2.

[22] Istat (1997a), Contabilità Nazionale. Tomo 1 - Conti Economici Nazionali Anni 1970-95.

[23] Istat (1997b), Contabilità nazionale. Tomo 3 - Conti economici regionali.

[24] Istat, Annuario Statistico Italiano, various years. 
[25] King, M A. (1972), "Corporate Taxation and Dividend Behaviour: A further Comment", The Review of Economic Studies, 39, 231-34.

[26] Morrison C. (1988), "Quasi-Fixed Inputs in U.S. and Japanese Manufacturing: A Generalized Leontief Restricted Cost Function Approach", The Review of Economics and Statistics, Vol. 70, pp.275-287.

[27] Morrison C., A. Schwartz (1994), "Distinguishing External from Internal Scale Effects: The Case of Public Infrastructure", The Journal of Productivity Analysis, Vol. 5, pp. 249-270.

[28] Morrison C., A. Schwartz (1996a), "Public Infrastructure, Private Input Demand, and Economic Performance in New England Manufacturing", Journal of Business 86 Economic Statistics, Vol. 14, No. 1, pp. 91-105.

[29] Morrison C., A. Schwartz (1996b), "State Infrastructure and Productive Performance", The American Economic Review Vol. 86, No. 5, pp.1095-1112.

[30] Munnell, A. (1990a), "Why Has Productivity Growth Declined? Productivity and Public Investment", New England Economic Review, 3-22.

[31] Munnell, A. (1990b), "How Does Public Infrastructure Affect Regional Economic Performance?", in A. Munnell (ed.), Is There A Shortfall In Public Capital Investment?, Boston: Federal Reserve Bank of Boston.

[32] Picci L.(1995a), "Productivity and Infrastructure in the Italian Regions", working paper, Dipartimento di Scienze Economiche, Università di Bologna.

[33] Picci, L. (1995b), "Il capitale mancante nel Mezzogiorno italiano", working paper, Dipartimento di Scienze Economiche, Università di Bologna.

[34] Prosperetti, L., F. Varetto (1991), I differenziali di produttività Nord-Sud nel settore manifatturiero, Il Mulino, Bologna.

[35] Rosa G. (1979), Lo stock di capitale nell'industria italiana: Nuove stime settoriali e territoriali, Roma, SIPI. 
[36] Rossi N., G. Toniolo (1993), "Un secolo di sviluppo economico", Rivista di Storia Economica, Bologna, Il Mulino.

[37] Rossi, Sorgato and Toniolo (1993), "I conti economici italiani: una ricostruzione statistica", Rivista di Storia Economica, 10, 1-47.

[38] Seitz H., G. Licht (1995), "The Impact of Public Infrastructure Capital on Regional Manufacturing Production Costs", Regional Studies, Vol. 29, No. 3, pp.231-240.

[39] SVIMEZ (1993), I conti economici del Centro-Nord e del Mezzogiorno nel ventennio 1970-1989, Il Mulino, Bologna. 


\section{Appendix A. Cobb Douglas cost function}

In our analysis we distinguish between variable inputs (labor, $L$, and private capital in transportation, $K T$ ), and quasi-fixed inputs (public capital, $K G$, and private capital in buildings and machinery, $K B$ and $K M$ respectively, with $K B+K M+K T=K)$. Variable costs, $G$, depend on the price of the variable factors, on the level of output, on the state of technology, and on the level of the quasi-fixed inputs:

$$
G=G\left(p_{L}, p_{K T}, Q, A, K M, K B, K G\right)
$$

Total costs are given by:

$$
C=G+p_{K M} K M+p_{K B} K B
$$

where we are assuming that $K G$ has a price of zero for the firm.

For a Cobb Douglas technology, $Q=A K T^{a} L^{b}$, conditional factor demands for variable inputs are given by:

$$
\begin{aligned}
X_{L}^{*} & =A^{-\frac{1}{a+b}}\left[\frac{a}{b} \frac{p_{L}}{p_{K T}}\right]^{-\frac{a}{a+b}} Q^{\frac{1}{a+b}} K G^{-\frac{g}{a+b}} K M^{-\frac{m}{a+b}} K B^{-\frac{d}{a+b}}, \\
X_{K T}^{*} & =A^{-\frac{1}{a+b}}\left[\frac{a}{b} \frac{p_{L}}{p_{K T}}\right]^{\frac{b}{a+b}} Q^{\frac{1}{a+b}} K G^{-\frac{g}{a+b}} K M^{-\frac{m}{a+b}} K B^{-\frac{d}{a+b}},
\end{aligned}
$$

and

$$
G\left(p_{L}, p_{K T}, Q, A, K G, K M\right)=p_{L} X_{L}^{*}+p_{K T} X_{K T}^{*}
$$

Assuming constant returns to variable inputs, $a+b=1$, and taking logs, yields

$$
\log G / Q=-A-g \log K G-m \log K M-d \log K B+\log \Psi+b \log p_{L}+a \log p_{K T}
$$

where $\Psi \equiv\left(a^{a} b^{b}\right)^{-\frac{1}{v}}$. Then, by Shepard's Lemma:

$$
\beta_{j}=\frac{\partial \log G}{\partial \log p_{j}}=\frac{\partial G}{\partial p_{j}} \frac{p_{j}}{G}=\frac{p_{j} X_{j}}{G}=S_{j}, \quad j=1,2,
$$

where $X_{1}=L, X_{2}=K T, p_{1}=p_{L}$ and $p_{2}=p_{K T}$.

We estimate the system of equations formed by the log cost function (19), a factor share equation (20) and the optimality condition (the price of output equals 
the marginal cost). ${ }^{15}$ We add fixed effects, a time trend to proxy for technological improvements, and estimate the resulting three equation system by (iterative) SUR, see e.g. Greene (1997), pp. 689-98, or Berndt (1991) ch. 9 for details. Using the estimated parameters, we can calculate the quantities in (10), (11), and (12).

\section{Appendix B. Generalized Leontief Cost Function}

Following Morrison (1988) and Morrison and Schwartz (1994, 1996), a Generalized Leontief specification for the variable cost function $G$ in $(9)$ is:

$$
\begin{aligned}
G(x, p, t, Q)= & Q\left(\sum_{i} \sum_{j} \alpha_{i j} p_{i}^{0.5} p_{j}^{0.5}+\sum_{i} \sum_{m} \delta_{i m} p_{i} s_{m}^{0.5}+\sum_{i} p_{i} \sum_{m} \sum_{n} \gamma_{m n} s_{m}^{0.5} s_{n}^{0.5}\right) \\
& +Q^{-0.5}\left(\sum_{i} \sum_{k} \delta_{i k} p_{i} x_{k}^{0.5}+\sum_{i} p_{i} \sum_{m} \sum_{k} \gamma_{m k} s_{m}^{0.5} x_{k}^{0.5}\right) \\
& +\sum_{i} p_{i} \sum_{k} \sum_{h} \gamma_{h k} x_{k}^{0.5} x_{h}^{0.5}
\end{aligned}
$$

with symmetry in the parameters imposed, e.g., $\alpha_{i j}=\alpha_{j i}$. In (21), $x$ indicates quasifixed inputs subject to homogeneity conditions: $K G, K B$ and $K M ; p$ are the prices of variable inputs $(L$ and $K T) ; s$ denotes the remaining arguments: a time trend $(t)$, that proxies technological progress, and output $(Q) .{ }^{16}$

To estimate all the parameters of (21), we construct a system that includes the two variable input demand equations, the profit maximization condition, and (21) itself. The variable input demand equations are the derivatives of $G$ with respect to $p$ (by Shepard's lemma):

$$
\begin{aligned}
\frac{V_{j}}{Q}= & \frac{\partial G}{\partial p_{j}} \frac{1}{Q}=\sum_{i} \alpha_{j i} \frac{p_{i}^{0.5}}{p_{j}^{0.5}}+\sum_{m} \delta_{j m} s_{m}^{0.5}+\sum_{m} \sum_{n} \gamma_{m n} s_{m}^{0.5} s_{n}^{0.5} \\
& +Q^{-0.5}\left(\sum_{k} \delta_{j k} x_{k}^{0.5}+\sum_{m} \sum_{k} \gamma_{m k} s_{m}^{0.5} x_{k}^{0.5}\right)
\end{aligned}
$$

\footnotetext{
${ }^{15}$ Notice that, by construction, the two share equations in (20) have the property that, at each time period, the sum of the dependent variables equals one. Hence, we can drop one share equation.

${ }^{16}$ Notice that this specification for the cost function only ensures linear homogeneity in prices. Convexity in the quasi fixed inputs and concavity in prices is not guaranteed. It can be either imposed a priori by imposing sign constraints on certain parametes, or checked ex post, see Morrison (1988) for details.
} 


$$
+Q^{-1} \sum_{k} \sum_{h} \gamma_{h k} x_{k}^{0.5} x_{h}^{0.5}
$$

for $j=1,2$

where $V_{1}=L, V_{2}=K T$, and we standardize by $Q$ to reduce problems of heteroskedasticity.

Next, profit maximization requires equality of output price and marginal cost, so that

$$
\begin{aligned}
p_{Q}= & \frac{\partial G}{\partial Q}=\sum_{i} \sum_{j} \alpha_{i j} p_{i}^{0.5} p_{j}^{0.5}+\sum_{i} \sum_{M j} \delta_{i m} p_{i} s_{m}^{0.5}+\sum_{i} p_{i} \sum_{m} \sum_{n} \gamma_{m n} s_{m}^{0.5} s_{n}^{0.5} \\
& +0.5 Q^{-0.5}\left(\sum_{i} \sum_{k} \delta_{i k} p_{i} x_{k}^{0.5}+\sum_{i} p_{i} \sum_{m} \sum_{k} \gamma_{m k} s_{m}^{0.5} x_{k}^{0.5}\right) \\
& +0.5 Q^{0.5}\left(\sum_{i} \delta_{i Y} p_{i}+\sum_{i} p_{i} \sum_{m} \gamma_{m Y} s_{m}^{0.5}\right)+0.5 \sum_{i} p_{i} \sum_{k} \gamma_{Y k} x_{k} .
\end{aligned}
$$

To conclude, notice that the four equation system made up of (21), (22), and (23) has a rather complex structure, but it is linear in the parameters. Hence, we can estimate it by (iterative) SUR, after adding fixed effects to account for regional disparities. Using the estimated parameters, we calculate the quantities in (10), (11), and (12).

\section{Appendix C. The Data}

Output: regional series for manufacturing value-added in current and constant 1990 prices are obtained from Istat (1997b) for the period 1980-1994 and from Fondazione Eni - Enrico Mattei (1994), for previous years (time series data on expenditures on energy and intermediate inputs for the manufacturing sector are not available on a regional basis).

The price of output is measured as the implicit price deflator computed for each region as the ratio of current and constant liras value added.

Labor: number of workers employed in the manufacturing sector is obtained combining data from Annuario Statistico Italiano (Istat, various years) and Svimez (1993). The nominal value of wages for production and nonproduction workers is 
taken to be the same, since no data are available for the latter. Regional consumer price indexes (Istat, 1997a) are used to obtain real wages.

Private capital: The quantity of private capital, $K$, is measured as the private capital in the manufacturing sector in 1990 liras. We have estimated regional stocks of capital for each category of capital good (buildings, plant, equipment and machinery, transportation) applying the perpetual inventory method (assuming constant depreciation within each group). Istat (1997b) provides regional investment data on nominal and constant investment over the period 1980-1997. Different sources have been used to build regional series covering the whole period needed in order to apply the perpetual inventory method. Regional investments on the three categories are obtained by applying to these series the same weights observed at the national level over the same period. Usual hypotheses on depreciation are made. The benchmark for the capital stock in buildings is taken from Istat (1995).

Factor prices for capital inputs: we use the concept of user cost of private capital. The effective rental price of capital, $p_{K}^{E}$, is obtained adjusting the implicit price deflator for taxation and subsidies:

$$
p_{K}^{E}=p_{K}[1-u s]
$$

with us standing for savings per unit, i.e.,

$$
u s=\frac{1}{1+\rho(1-\tau)}\left[\frac{C C}{I}+\sum_{i=1}^{n} \frac{a_{i}+b_{i}}{(1+\rho)^{i}}\right]
$$

where $\rho$ is the discount rate (that we assume equal to the interest rate charged by special investment banks called Istituti di Credito Speciale), $\tau$ is the tax rate on profits, $C C$ are government contributions to buy industrial capital given through Cassa del Mezzogiorno ${ }^{17}, I$ are investments in the industrial sector, $a$ and $b$ are normal and ahead depreciation coefficients.

Public capital: the stock of public capital is measured as end-of-year publiccapital stock of and, Communications,Public Buildings, Water, Sanitation, Roads,

\footnotetext{
${ }^{17}$ We use commitments rather than disbursements because the former are more relevant for investment decisions by firms.
} 
Railways, Marine and Other (e.g., gas-pipelines, infrastructures for tourism). These data are computed by Bonaglia and Picci (1999) applying the perpetual inventory method to the series of public spending in infrastructure ("lavori eseguiti", Istat, Opere Pubbliche ).

\begin{tabular}{lll}
$\begin{array}{l}\text { Variable } \\
\text { Name }\end{array}$ & Istat Category & Description \\
\hline \hline Roads & $\begin{array}{l}\text { 1. Roads } \\
\text { 2. Airports }\end{array}$ & $\begin{array}{l}\text { Highways and all kinds of roads } \\
\text { Landing strips, buildings }\end{array}$ \\
\hline Rail & 3. Railways & Railways, subways, cable-railway \\
\hline Mar & 4. Marine & Ports, lake and river navigation \\
\hline Water & 5. Water & River planning \\
& 6. Energy & Electric grid, power plants \\
\hline Com & 7. Communications & Telecommunications plants \\
\hline Educ & 8. Schools and social facilities & Schools, universities \\
& 9. Public buildings & Monuments, penitentiaries \\
& 10. Residential buildings & Subsidized buildings, reconstruction after calamity \\
\hline San & 11. Sanitation & Hospitals, water-filtering, water cysterns, sewers \\
\hline Land & 12. Land reclaimation & Land reclaimation and irrigation \\
& 13. Land transformation & Land improvement \\
\hline Other & 14. Other & Gas-pipelines, infrastructures for tourism \\
\hline \hline
\end{tabular}

Finally, our macroregions are defined as follows:

Macroregion Regions included

North West Piemonte, Val d'Aosta, Lombardia, Liguria

North East Trentino Alto Adige, Veneto, Friuli Venezia Giulia, Emilia Romagna

Center Toscana, Umbria, Marche, Lazio

South Abruzzo, Molise, Campania, Puglia,

Basilicata, Calabria, Sicilia, Sardegna 
Table C.1: Production function, 2SLS without influential observations

\begin{tabular}{l|ccccc} 
& Italy & North-West & North-East & Centre & South \\
\hline $\mathrm{KG}$ & $-.219^{* *}$ & -.062 & $-.190^{* *}$ & .144 & .089 \\
& $(.048)$ & $(.160)$ & $(.090)$ & $(.257)$ & $(.164)$ \\
$\mathrm{K}$ & $.183^{* *}$ & $-.296^{*}$ & $-.428^{* *}$ & $.356^{* *}$ & $.188^{* *}$ \\
& $(.019)$ & $(.171)$ & $(.101)$ & $(.043)$ & $(.029)$ \\
$\mathrm{L}$ & $.670^{* *}$ & $.946^{* *}$ & $.855^{* *}$ & $.647^{* *}$ & $.380^{* *}$ \\
& $(.043)$ & $(.194)$ & $(.087)$ & $(.076)$ & $(.089)$ \\
Const & $-1.692^{* *}$ & $1.354^{* *}$ & $1.440^{* *}$ & $1.025^{* *}$ & $-1.338^{* *}$ \\
& $(.022)$ & $(.064)$ & $(.030)$ & $(.049)$ & $(.054)$ \\
\hline $\mathrm{R}^{2}$ adj & .99 & .99 & .99 & .99 & .99 \\
$\mathrm{~N}^{\circ}$ obs & 406 & 86 & 86 & 86 & 137 \\
Hausmann & .00 & .32 & .05 & .01 & .00 \\
(p-value) & & & & \\
\hline \hline
\end{tabular}

Dependent variable is (log of) value added; $K G, K$ and $L$ are in logarithms.

Instruments are KGlag and KGnb.

${ }^{*}$ and ${ }^{* *}$ indicate significance at the $10 \%$ and $5 \%$ level respectively.

Standard errors are in parentheses.

Outlying observations are discarded using the Dfbeta method. 
Table 1:Summary Statistics

\begin{tabular}{|c|c|c|c|c|c|}
\hline Average annual growth rate of: & ITALY & North-West & North-East & Center & South \\
\hline \multicolumn{6}{|l|}{ FULL SAMPLE } \\
\hline Real value-added & $\begin{array}{c}.020 \\
(.057)\end{array}$ & $\begin{array}{c}.009 \\
(.059)\end{array}$ & $\begin{array}{c}.029 \\
(.053)\end{array}$ & $\begin{array}{c}.025 \\
(.047)\end{array}$ & $\begin{array}{c}.019 \\
(.062)\end{array}$ \\
\hline \multirow[t]{2}{*}{ Private Capital $^{(a)}$} & .010 & .006 & .009 & .009 & .013 \\
\hline & $(.012)$ & $(.007)$ & $(.005)$ & $(.007)$ & $(.017)$ \\
\hline \multirow[t]{2}{*}{ Labor $^{(a)}$} & -.003 & -.012 & -.002 & -.001 & -.001 \\
\hline & $(.025)$ & $(.023)$ & $(.022)$ & $(.024)$ & $(.027)$ \\
\hline \multirow[t]{2}{*}{ Total factor productivity } & .013 & .015 & .022 & .017 & .006 \\
\hline & $(.050)$ & $(.056)$ & $(.044)$ & $(.036)$ & $(.056)$ \\
\hline \multirow{2}{*}{ Public Capital } & .027 & .030 & .031 & .023 & .025 \\
\hline & $(.014)$ & $(.015)$ & $(.013)$ & $(.012)$ & $(.014)$ \\
\hline \multicolumn{6}{|l|}{$1970-1979$} \\
\hline \multirow[t]{2}{*}{ Real value-added } & .031 & .007 & .046 & .041 & .030 \\
\hline & $(.070)$ & $(.083)$ & $(.066)$ & $(.059)$ & $(.068)$ \\
\hline \multirow[t]{2}{*}{ Private Capital $^{(a)}$} & .014 & .007 & .010 & .010 & .022 \\
\hline & $(.013)$ & $(.005)$ & $(.005)$ & $(.005)$ & $(.017)$ \\
\hline \multirow[t]{2}{*}{ Labor $^{(a)}$} & .004 & -.008 & .006 & .009 & .006 \\
\hline & $(.022)$ & $(.016)$ & $(.015)$ & $(.027)$ & $(.022)$ \\
\hline \multirow[t]{2}{*}{ Total factor productivity } & .013 & .007 & .030 & .022 & .002 \\
\hline & $(.062)$ & $(.076)$ & $(.059)$ & $(.047)$ & $(.060)$ \\
\hline \multirow{2}{*}{ Public capital } & 0.32 & .027 & .030 & .029 & .037 \\
\hline & $(.014)$ & $(.008)$ & $(.013)$ & $(.015)$ & $(.015)$ \\
\hline \multicolumn{6}{|l|}{$1980-1989$} \\
\hline \multirow[t]{2}{*}{ Real value-added } & .017 & .017 & .020 & .018 & .015 \\
\hline & $(.048)$ & $(.040)$ & $(.043)$ & $(.037)$ & $(.059)$ \\
\hline \multirow[t]{2}{*}{ Private Capital $^{(a)}$} & .009 & .007 & .009 & .011 & .008 \\
\hline & $(.012)$ & $(.008)$ & $(.004)$ & $(.009)$ & $(.017)$ \\
\hline \multirow[t]{2}{*}{ Labor $^{(a)}$} & -.006 & -.013 & -.003 & -.008 & -.003 \\
\hline & $(.025)$ & $(.026)$ & $(.023)$ & $(.022)$ & $(.027)$ \\
\hline \multirow[t]{2}{*}{ Total factor productivity } & .014 & .023 & .014 & .015 & .010 \\
\hline & $(.046)$ & $(.041)$ & $(.034)$ & $(.029)$ & $(.059)$ \\
\hline \multirow[t]{2}{*}{ Public Capital } & .025 & .033 & .033 & .020 & .020 \\
\hline & $(.014)$ & $(.020)$ & $(.013)$ & $(.007)$ & $(.007)$ \\
\hline \multicolumn{6}{|l|}{$1990-1994$} \\
\hline \multirow[t]{2}{*}{ Real value-added } & .007 & -.003 & .015 & .012 & .006 \\
\hline & $(.042)$ & $(.040)$ & $(.031)$ & $(.032)$ & $(.052)$ \\
\hline \multirow[t]{2}{*}{ Private Capital $^{(a)}$} & .005 & .001 & .005 & .004 & .007 \\
\hline & $(.008)$ & $(.006)$ & $(.006)$ & $(.005)$ & $(.009)$ \\
\hline \multirow[t]{2}{*}{$\operatorname{Labor}^{(a)}$} & -.011 & -.018 & -.014 & -.006 & -.007 \\
\hline & $(.027)$ & $(.025)$ & $(.026)$ & $(.018)$ & $(.032)$ \\
\hline \multirow[t]{2}{*}{ Total factor productivity } & .013 & .014 & .024 & .014 & .006 \\
\hline & $(.034)$ & $(.040)$ & $(.025)$ & $(.027)$ & $(.038)$ \\
\hline \multirow[t]{2}{*}{ Public capital } & .021 & .030 & .028 & .017 & .014 \\
\hline & $(.012)$ & $(.014)$ & $(.010)$ & $(.008)$ & $(.006)$ \\
\hline
\end{tabular}

Notes: Standard deviations are in parentheses.

(a) Private Capital is $S^{K} \dot{K}$; Labor is $S^{L} \dot{L}$; 
Table 2: Growth accounting

\begin{tabular}{l|cccccccc} 
& Italy & $\begin{array}{c}\text { Italy } \\
1970-79\end{array}$ & $\begin{array}{c}\text { Italy } \\
1980-89\end{array}$ & $\begin{array}{c}\text { Italy } \\
1990-94\end{array}$ & $\begin{array}{c}\text { North- } \\
\text { West }\end{array}$ & $\begin{array}{c}\text { North- } \\
\text { East }\end{array}$ & Center & South \\
\hline$\dot{K} G$ & $0.471^{* *}$ & .240 & $.820^{* *}$ & .535 & 0.449 & -0.144 & 0.398 & $0.616^{* *}$ \\
& $(.188)$ & $(.437)$ & $(.381)$ & $(.639)$ & $(.448)$ & $(.463)$ & $(.338)$ & $(.313)$ \\
$\dot{K}$ & $0.138^{* *}$ & .023 & $-.44^{* *}$ & .035 & -0.317 & 0.276 & -0.022 & $-0.178^{* *}$ \\
& $(.061)$ & $(.121)$ & $(.145)$ & $(.219)$ & $(.262)$ & $(.227)$ & $(.141)$ & $(.08)$ \\
Const & 0.006 & .004 & .005 & .001 & 0.009 & 0.017 & 0.009 & -0.001 \\
& $. .006)$ & $(.017)$ & $(.011)$ & $(.013)$ & $(.017)$ & $(0.016)$ & $(.009)$ & $(.008)$ \\
\hline $\mathrm{R}^{2}$ & 0.02 & .01 & .07 & .01 & 0.02 & 0.01 & 0.01 & 0.04 \\
$\mathrm{~N}^{o}$ obs & 480 & 180 & 200 & 100 & 96 & 96 & 96 & 192 \\
\hline \hline
\end{tabular}

Dependent variable is TFP growth

* and ** indicate significance at the $10 \%$ and $5 \%$ level respectively

Standard errors are in parentheses

Table 3: Production function

\begin{tabular}{l|cccccccc} 
& Italy & $\begin{array}{c}\text { Italy } \\
1970-79\end{array}$ & $\begin{array}{c}\text { Italy } \\
1980-89\end{array}$ & $\begin{array}{c}\text { Italy } \\
1990-94\end{array}$ & $\begin{array}{c}\text { North- } \\
\text { West }\end{array}$ & $\begin{array}{c}\text { North- } \\
\text { East }\end{array}$ & Center & South \\
\hline $\mathrm{KG}$ & $-.148^{* *}$ & -.085 & $.176^{*}$ & $.559^{* *}$ & -.139 & $-.141^{*}$ & .147 & $.367^{* *}$ \\
& $(.048)$ & $(.132)$ & $(.094)$ & $(.194)$ & $(.113)$ & $(.072)$ & $(.206)$ & $(.151)$ \\
$\mathrm{K}$ & $.144^{* *}$ & $.082^{* *}$ & .022 & $.418^{* *}$ & $-.349^{* *}$ & $-.325^{* *}$ & $.370^{* *}$ & $.216^{* *}$ \\
& $(.020)$ & $(.037)$ & $(.053)$ & $(.126)$ & $(.143)$ & $(.087)$ & $(.043)$ & $(.025)$ \\
$\mathrm{L}$ & $.748^{* *}$ & $1.189^{* *}$ & $.465^{* *}$ & $.490^{* *}$ & $.907^{* *}$ & $.938^{* *}$ & $.454^{* *}$ & $.289^{* *}$ \\
& $(.043)$ & $(.101)$ & $(.076)$ & $(.081)$ & $(.202)$ & $(.083)$ & $(.082)$ & $(.087)$ \\
Const & $2.657^{* *}$ & 1.349 & $3.758^{* *}$ & -3.256 & $6.701^{* *}$ & $9.593^{* *}$ & 1.860 & 1.516 \\
& $(.536)$ & $(1.225)$ & $(1.113)$ & $(2.690)$ & $(1.574)$ & $(.808)$ & $(1.865)$ & $(1.507)$ \\
\hline $\mathrm{R}^{2}$ & .98 & .98 & .94 & .94 & .91 & .93 & .99 & .96 \\
$\mathrm{~N}^{o}$ obs & 500 & 200 & 200 & 100 & 100 & 100 & 125 & 200 \\
CRS (p-value $)^{(a)}$ & .00 & .16 & .01 & .07 & .01 & .00 & .87 & .33 \\
\hline \hline
\end{tabular}

Dependent variable is (log of) value added; $K G, K$ and $L$ are in logarithms.

${ }^{*}$ and ${ }^{* *}$ indicate significance at the $10 \%$ and $5 \%$ level respectively

Standard errors are in parentheses

(a) The null hypothesis is constant returns to scale to $K G, K$ and $L$ 
Table 4: Cost Function (Cobb Douglas)

\begin{tabular}{l|cccccccc} 
& Italy & Italy 70-79 & Italy 80-89 & Italy 90-94 & North-West & North-East & Center & South \\
\hline & & & & & & & & \\
$\varphi_{K G}$ & -.029 & .049 & -.085 & -.029 & -.171 & -.086 & .202 & .016 \\
$E_{K G}$ & .275 & .181 & .338 & .298 & .491 & .300 & .092 & .371 \\
$E_{K M}$ & -.022 & .051 & -.057 & .179 & -.090 & .177 & .041 & .088 \\
$E_{K B}$ & .198 & .029 & .395 & -.115 & .223 & -.027 & .128 & .149 \\
& & & & & & & & \\
\hline$N^{o}$ obs & 500 & 200 & 200 & 100 & 100 & 100 & 100 & 200 \\
\hline \hline
\end{tabular}

$\varphi_{x}$ is the shadow share of input $x$.

$E_{x}$ is $\left(U_{X}-Z_{X}\right) x / C$, where $U_{X}$ is the user cost of $x$, and $C$ represents total costs.

Table 5: Production function, no influential observations

\begin{tabular}{l|ccccc} 
& Italy & North-West & North-East & Center & South \\
\hline $\mathrm{KG}$ & $-.182^{* *}$ & .021 & $.164^{*}$ & .348 & $.283^{* *}$ \\
& $(.048)$ & $(.172)$ & $(.086)$ & $(.231)$ & $(.143)$ \\
$\mathrm{K}$ & $.166^{* *}$ & $-.379^{* *}$ & $-.478^{* *}$ & $.297^{* *}$ & $.195^{* *}$ \\
& $(.018)$ & $(.172)$ & $(.100)$ & $(.041)$ & $(.025)$ \\
$\mathrm{L}$ & $.683^{* *}$ & $1.055^{* *}$ & $.872^{* *}$ & $.611^{* *}$ & $.265^{* *}$ \\
& $(.042)$ & $(.207)$ & $(.084)$ & $(.077)$ & $(.082)$ \\
\hline $\mathrm{R}^{2}$ & .97 & .98 & .81 & .99 & .94 \\
$\mathrm{~N}^{o}$ obs & 471 & 90 & 88 & 115 & 190 \\
CRS (p-value $)^{(a)}$ & .00 & .21 & .00 & .19 & .04 \\
\hline \hline
\end{tabular}

Dependent variable is (log of) value added; $K G, K$ and $L$ are in logarithms. * and ${ }^{* *}$ indicate significance at the $10 \%$ and $5 \%$ level respectively Standard errors are in parentheses

(a) The null hypothesis is constant returns to scale to KG, K and L Outlying observations are discarded using the Dfbeta method 
Table 6: Production function, two stage least squares

\begin{tabular}{lccccc} 
& Italy & North-West & North-East & Center & South \\
\hline $\mathrm{KG}$ & $-.161^{* *}$ & -.159 & $-.134^{*}$ & .221 & .184 \\
& $(.048)$ & $(.108)$ & $(.075)$ & $(.224)$ & $(.174)$ \\
$\mathrm{K}$ & $.173^{* *}$ & $-.331^{* *}$ & $-.342^{* *}$ & $.382^{* *}$ & $.242^{* *}$ \\
& $(.022)$ & $(.145)$ & $(.091)$ & $(.044)$ & $(.028)$ \\
$\mathrm{L}$ & $.702^{* *}$ & $.850^{* *}$ & $.927^{* *}$ & $.482^{* *}$ & $.314^{* *}$ \\
& .045 & $(.196)$ & $(.083)$ & $(.074)$ & $(.096)$ \\
Const & $1.229^{* *}$ & $1.366^{* *}$ & $-1.972^{* *}$ & $-1.487^{* *}$ & $1.064^{* *}$ \\
& $(.022)$ & $(.067)$ & $(.035)$ & $(.049)$ & $(.057)$ \\
\hline $\mathrm{R}^{2}$ adj & .99 & .99 & .99 & .99 & .99 \\
$\mathrm{~N}^{o}$ obs & 432 & 96 & 96 & 96 & 144 \\
Hausmann & .01 & .43 & .09 & .05 & .00 \\
(p-value) & .01 & & & & \\
\hline \hline
\end{tabular}

Dependent variable is (log of) value added; $K G, K$ and $L$ are in logarithms. Instruments are KGlag and KGnb.

* and ${ }^{* *}$ indicate significance at the $10 \%$ and $5 \%$ level respectively Standard errors are in parentheses

Table 7: Cost Function (Generalized Leontief)

\begin{tabular}{l|cccccccc} 
& Italy & Italy 70-79 & Italy 80-89 & Italy 90-94 & North-West & North-East & Center & South \\
\hline$\varphi_{K G}$ & -.139 & -.155 & -.223 & .139 & -.252 & .190 & -.003 & -.259 \\
$E_{K G}$ & .385 & .374 & .500 & .137 & .395 & .021 & .294 & .660 \\
$E_{K M}$ & .035 & .076 & .208 & .199 & .093 & .472 & .195 & .265 \\
$E_{K B}$ & .190 & .239 & -.004 & .385 & -.171 & .125 & .234 & -.178 \\
\hline$N^{\circ}$ obs & 500 & 200 & 200 & 100 & 100 & 100 & 100 & 200 \\
\hline \hline
\end{tabular}

$\varphi_{x}$ is the shadow share of input $x$.

$E_{x}$ is $\left(U_{X}-Z_{X}\right) x / C$, where $U_{X}$ is the user cost of $x$, and $C$ represents total costs. 